\title{
Sending Signals
}

\section{Dear Reader,}

Samsung SDI and LG Chem are to produce battery cell modules for Audi for use in electric vehicles, supplying them from plants in Europe. This statement by the Ingolstadt-based car maker sends a clear signal regarding the positioning of electric vehicles from German OEMs, something that had previously been unconvincing. While some experts were uncertain about the credibility of the move in the first days after the announcement and others dismissed it as a purely image-building exercise, Prof. Dr. Ulrich Hackenberg, Audi's Board Member for Technical Development, confirmed the deal in an interview: "We are getting serious."

This commitment by the two battery cell manufacturers will have powerful repercussions, both economically and technically, for several reasons. It will mean huge investment by the South Koreans. And this investment will be worthwhile only with representative sales guarantees in Europe, as until now they have succeeded in supplying their products from Asia. Other OEMs will certainly benefit from Audi's advance. The premium brand traditionally has the role of technology leader in the VW Group and will ensure representative sales volumes.

According to Hackenberg, the charm of this offensive lies above all in the competitiveness of the companies, which will influence costs and also guarantee a secure supply chain. The previous Japanese VW partner Sanyo/Panasonic seems to be out of the running for the time being, even though Hackenberg denies this, which means that the Korean cell manufacturers will be directly competing with each other. At the same time, there is also competition between different technologies. Samsung produces prismatic cells, while LG Chem prefers pouch cell technology. Both types have good perspectives for the future, and no car maker is likely to come out in favour of one or the other over the next few years.

Audi is expected to be ready in 2018 . That may be late, but it does send a signal. The cells manufactured in Europe will then be used for the first time in an Audi SUV that is designed exclusively as a fully electric vehicle.

Sending a signal has a further aspect. Well-informed sources suspect a certain reluctance on the part of Sanyo/Panasonic. They claim that the Japanese only trust the Japanese. And companies like Toyota and Honda are conservative or even sceptical when it comes to batterypowered vehicles, they say. Toyota is more interested in the fuel cell and shies away from high-energy cells with up to $60 \mathrm{Ah}$.

The IAA 2015 in Frankfurt was marked by driver assistance systems. In 2017, it will be electric vehicles that will assist the internal combustion engine - in hybrid drive systems and fleet consumption calculations. That is the opinion of experts who consider the current stagnation in electric mobility to be dangerous.

Kind regards,

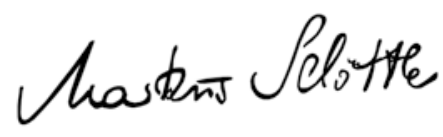

Markus Schöttle

Deputy Editor in Chief

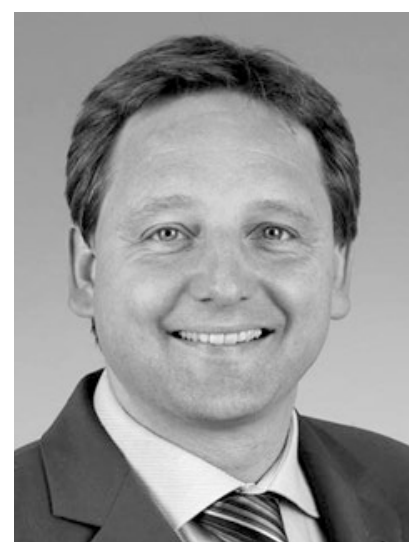

